\title{
Intestinal TM7 bacterial phylogenies in active inflammatory bowel disease
}

\section{Correspondence \\ Stephan J. Ott \\ s.ott@mucosa.de}

Received 25 October 2007

Accepted 24 August 2008

\author{
Tanja Kuehbacher, ${ }^{1} \dagger$ Ateequr Rehman, ${ }^{2} \dagger$ Patricia Lepage ${ }^{2}$ \\ Stephan Hellmig, ${ }^{1}$ Ulrich R. Fölsch, ${ }^{1}$ Stefan Schreiber ${ }^{1,2}$ \\ and Stephan J. Ott ${ }^{1,2}$
}
${ }^{1}$ Clinic for General Internal Medicine, I. Medical Department, University Hospital Schleswig-Holstein (UKSH), Campus Kiel, Brunswiker Str. 10, D-24105 Kiel, Germany
${ }^{2}$ Institute for Clinical Molecular Biology (IKMB), Christian-Albrechts-Universität (CAU) Kiel, Schittenhelmstr. 12, D-24105 Kiel, Germany

TM7 is a recently described subgroup of Gram-positive uncultivable bacteria originally found in natural environmental habitats. An association of the TM7 bacterial division with the inflammatory pathogenesis of periodontitis has been previously shown. This study investigated TM7 phylogenies in patients with inflammatory bowel diseases (IBDs). The mucosal microbiota of patients with active Crohn's disease (CD; $n=42)$ and ulcerative colitis (UC; $n=31$ ) was compared with that of controls $(n=33)$. TM7 consortia were examined using molecular techniques based on 16S rRNA genes, including clone libraries, sequencing and in situ hybridization. TM7 molecular signatures could be cloned from mucosal samples of both IBD patients and controls, but the composition of the clone libraries differed significantly. Taxonomic analysis of the sequences revealed a higher diversity of TM7 phylotypes in CD (23 different phylotypes) than in UC (10) and non-IBD controls (12). All clone libraries showed a high number of novel sequences (21 for controls, 34 for CD and 29 for UC). A highly atypical base substitution for bacterial $16 \mathrm{~S}$ rRNA genes associated with antibiotic resistance was detected in almost all sequences from CD (97.3\%) and UC (100\%) patients compared to only $65.1 \%$ in the controls. TM7 bacteria might play an important role in IBD similar to that previously described in oral inflammation. The alterations of TM7 bacteria and the genetically determined antibiotic resistance of TM7 species in IBD could be a relevant part of a more general alteration of bacterial microbiota in IBD as recently found, e.g. as a promoter of inflammation at early stages of disease.

\section{INTRODUCTION}

Inflammatory bowel diseases (IBDs) are characterized by chronic-intermittent inflammation of the intestinal mucosa. The pathophysiology of IBD is multifactorial and based upon a complex interaction of genetic, immunological and environmental factors leading to a substantial defect of the intestinal mucosal barrier (Eckburg \& Relman, 2007; Schreiber et al., 2005). The gut microbiota was previously identified as an essential part of intestinal mucosal barrier function and maintenance of barrier function is strongly associated with the integrity of the intestinal microbiota (Hooper \& Gordon, 2001). The composition of the intestinal microbiota

†These authors contributed equally to this work.

Abbreviations: $\mathrm{CD}$, Crohn's disease; IBD, inflammatory bowel disease; OTUs, operational taxonomic units; UC, ulcerative colitis.

The GenBank/EMBL/DDBJ accession numbers for the TM7 clone sequences are EU056368-EU056522 and EU056524-EU056533. represents a high diversity of different species, which have established complex and opportunistic interactions with the host during evolution (Hooper et al., 1998; Hooper \& Gordon, 2001). Alterations of the sensible equilibrium of microbial populations through environmental or yet unidentified factors contribute to a breakdown of intestinal barrier function and are therefore a hallmark of gastrointestinal inflammation (Manichanh et al., 2006; Marteau, 2000; Ott et al., 2004; Seksik et al., 2003).

The intestinal microbiota is composed of more than 500 different bacterial species (Hugenholtz et al., 1998). The exact composition of the intestinal microbiota is still unclear, since only a small part is amenable to cultivation. The introduction of molecular microbiology fundamentally revolutionized our understanding of the intestinal microbiota and facilitated the investigation of yet uncultivable bacteria (Hugenholtz et al., 1998), the more so as we now have access to specific bacterial populations which may be involved in the pathophysiology of inflammatory diseases. 
TM7 is a recently described subgroup of Gram-positive uncultivable bacteria associated with oral inflammation (Brinig et al., 2003). The TM7 bacterial division was originally described in natural environmental habitats such as soil, fresh- and seawater, deep-sea sediments, groundwater and hot springs (Brinig et al., 2003; Hugenholtz et al., 2001; Kumar et al., 2003; Ouverney et al., 2003). Original PCR clonal studies were based on a peat bog. In animals, TM7 has been found in termite guts and mouse faeces. In humans, TM7 has been detected in subgingival plaque, and studies showed an association of the TM7 bacterial division with inflammatory mucosal diseases, especially periodontitis and subgingival plaque (Brinig et al., 2003; Kumar et al., 2003; Ouverney et al., 2003). The TM7 division of bacteria has been suggested to play an important role in the early stages of inflammatory mucosal processes, probably by modifying growth conditions for competing bacterial populations.

In this study, we investigated the presence and diversity of the TM7 bacterial division in the human colonic mucosa of non-IBD controls and patients with active IBD.

\section{METHODS}

Recruitment of volunteers. Forty-two patients with active Crohn's disease $(\mathrm{CD})$ (median age 30 years, range 16-56 years; male/female 18/24; medication: 5-aminosalicylates $n=5$, cortisone $n=20$, azathioprine $n=1$ ), 31 patients with active ulcerative colitis (UC) (median age 41 years, range 23-74 years; male/female 19/12; medication: 5-ASA $n=15$, cortisone $n=6$, azathioprine $n=1$ ) and 33 non-IBD controls (median age 53 years, range 23-73 years; male/ female $9 / 24$; no medication) were enrolled in this study. The diagnosis of IBD was made in accordance with established clinical, endoscopic, histological and radiological criteria (Chapman et al., 1986; Malchow et al., 1984). Disease activity was assessed by the Crohn's disease activity index (CDAI) for CD and the clinical activity index (CAI) for UC. All patients with IBD were in an active phase of disease (CDAI $>150$ in the $\mathrm{CD}$ group and CAI $>4$ in the UC group). Colonic biopsies were sampled from macroscopic sites of inflammation. To assess the inflammatory activity, histological parameters were determined for IBD patients by two independent pathologists following the criteria described by Geboes and others (Geboes \& Dalle, 2002; Geboes et al., 2000). A non-inflammatory control group included healthy individuals (from screening colonoscopies but without pathological macroscopic or histological findings). Biopsies were taken from different segments of the colon. The inclusion criterion for all probands was that no antibiotic therapy at the time of investigation and in the last 6 months had been administered. Patient interviews on nutritional habits revealed no significant difference in the uptake of food containing fungal components (e.g. cheese) or in the use of parenteral or formula diets. The study was approved by the ethical committee of the Medical Faculty of the Christian-Albrechts University Kiel prior to its conduct. All study subjects gave written informed consent prior to colonoscopy. The detailed patient characteristics have been previously described (Ott et al., 2004).

DNA extraction and amplification of the 16S rRNA gene. Liquid nitrogen snap-frozen biopsy specimens were incubated with $200 \mu \mathrm{l}$ $\mathrm{TL}$ buffer and $25 \mu \mathrm{l}$ proteinase $\mathrm{K}$ at $55{ }^{\circ} \mathrm{C}$ for $2 \mathrm{~h}$ (PeqLab). DNA extraction was performed with the FastDNA spin kit as described earlier (Ott et al., 2004). The 16S rRNA gene coding region was amplified using a TM7-specific primer (TM7-580F; 5'

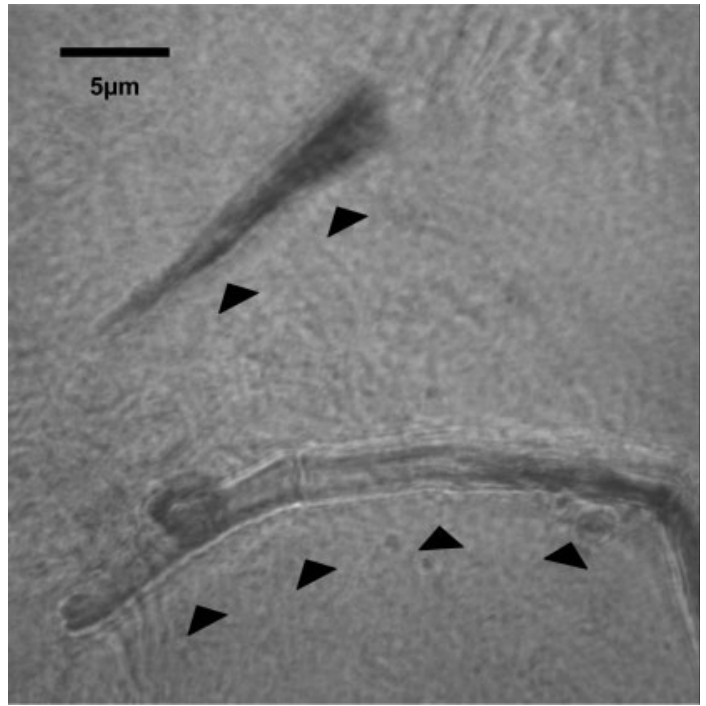

Fig. 1. In situ hybridization image of TM7 bacteria. Using in situ hybridization of colon tissue sections with a TM7-specific probe, the typical filamentous morphotype of the TM7 bacteria could be shown. The tissue was obtained from a control individual.

AYTGGGCGTAAAGAGTTGC-3') (Hugenholtz et al., 2001) and a universal primer for the bacterial domain (1492R; $5^{\prime}$ TACGGYTACCTTGTTACGACTT-3') (Hugenholtz et al., 2001). Amplification reactions were performed in a total volume of $50 \mu \mathrm{l}$ containing $1 \times$ PCR buffer, $15 \mathrm{mM} \mathrm{MgCl}_{2}$ (both Qiagen), $0.2 \mu \mathrm{M}$ each primer (Carl Roth), $0.2 \mu \mathrm{M}$ each deoxynucleoside triphosphate (Qiagen), 1 U DNA Taq polymerase (Qiagen) and 100 ng sample DNA. PCR amplification was performed in a GeneAmp PCR system 9700 (Applied Biosystems) using the following PCR program: $95{ }^{\circ} \mathrm{C}$ for $5 \mathrm{~min}$, and 35 cycles of $95{ }^{\circ} \mathrm{C}$ for $1 \mathrm{~min}, 50{ }^{\circ} \mathrm{C}$ for $1 \mathrm{~min}$, and $72{ }^{\circ} \mathrm{C}$ for $2 \mathrm{~min}$. One microlitre of PCR product was reamplified with the same protocol as above for 25 cycles. Reamplified PCR products were checked on a $1 \%$ agarose gel in $1 \times$ TAE buffer $(40 \mathrm{mM}$ Tris, $20 \mathrm{mM}$ acetic acid, $1 \mathrm{mM}$ EDTA, pH 8.3). DNA bands of the correct size (about $900 \mathrm{bp}$ ) were excised from the gel and purified by using the MinElute Gel Extraction kit (Qiagen).

Cloning and sequencing. Purified PCR amplicons of expected lengths were cloned by using the pCR 2.1 TOPO TA Cloning kit (Invitrogen) according to the manufacturer's guidelines. Insert was amplified by using vector specific primer M13F and M13R as described earlier (Ott et al., 2006). Sequencing of the inserts was performed on an ABI PRISM 3700 DNA analyser in a final volume of $10 \mu \mathrm{l}$ using $1 \mu \mathrm{l}$ ABI PRISM Big Dye (both Applied Biosystems) and a $1.6 \mu \mathrm{M}$ concentration of each primer (M13F or M13R) (Ott et al., 2006) using the following protocol: $90{ }^{\circ} \mathrm{C}$ for $3 \mathrm{~min}, 25$ cycles of $95{ }^{\circ} \mathrm{C}$ for $40 \mathrm{~s}, 55{ }^{\circ} \mathrm{C}$ for $40 \mathrm{~s}$ and $60{ }^{\circ} \mathrm{C}$ for $4 \mathrm{~min}$.

Phylogenetic analysis. The sequences were examined for chimeric artefacts using the CHIMERA-CHECK algorithm of the Ribosomal Database Project II (RDP-II; http://rdp.cme.msu.edu/) software package (Cole et al., 2003). Partial 16S rRNA gene sequences were subjected to a BLAST search (http://www.ncbi.nlm.nih.gov/BLAST/) against the GenBank nucleotide sequence database and Ribosomal Database Project II to define the closest relatives. The closest relative database and generated clone sequences were aligned with the CLUSTAL X program (Thompson et al., 1997; ftp://ftp-igbmc.u-strasbg.fr/pub/ClustalX/). Phylogenetic 
analysis was performed using the PHYLIP software package (version 3.64; http://evolution.genetics.washington.edu/phylip/getme.html). Distance and similarity matrices were calculated with the DNADIST program using the Jukes-Cantor correction. A neighbour-joining tree with bootstrap analysis (100 replications) was constructed.

Statistical analysis. Distance matrices created from the DNADIST program were used to perform rarefaction analysis and Chao I estimators of operational taxonomical unit (OTU) richness; the Shannon and Simpson index was calculated by using the DOTUR (Distance-Based OTU and Richness) program to characterize the diversity of TM7 bacteria (http://schloss.micro.umass.edu/software/) (Schloss \& Handelsman, 2005). OTUs were calculated at 1,2 and $3 \%$ difference levels.

The significance of difference in the composition between two libraries was calculated by using LIBSHUFF software as described previously (Schloss et al., 2004; Singleton et al., 2001). Bonferroni correction was used to calculate the critical $P$-value. The two libraries were considered to be significantly different from each other if the lower of the two $P$-values generated by LIBSHUFF was below or equal to the critical $P$-value (Wang et al., 2005) (the critical $P$-value for three clone libraries is 0.0085 , family wise error rate 0.05 ). The distance matrices for LIBSHUFF analysis were generated as stated above for DOTUR analysis. A standard coverage estimate was calculated as described by Good (1953), $C=1-(n / N)$, where $n$ is the number of OTUs that occurred only once in the library and $N$ is the total number of clones analysed.

For the different disease groups, a subgroup analysis was performed separately for gender, age and medication. No significant differences in the composition of the intestinal TM7 were found for these factors.

In situ hybridization. In situ hybridization was performed following previously established protocols (Forghani et al., 1985; Kerstens et al., 1994). Briefly, biopsy specimens were shock frozen in Tissue-Tek freezing medium, cut into $6 \mu \mathrm{m}$ sections using a cryomicrotome and placed on super frost glass slides (Menzel-Glaser). The 16S rRNA gene TM7 specific probe (TM7305 5'-GTCCCAGTCTGGCTGATC-3') (Hugenholtz et al., 2001) was labelled with biotin (Thermo Electron). After air-drying, tissue sections were treated with $3 \%$ hydrogen peroxide for $10 \mathrm{~min}$ at $37{ }^{\circ} \mathrm{C}$ to inactivate endogenous peroxidase. After a brief rinse in $0.01 \mathrm{M}$ PBS ( $\mathrm{pH} 7.3$ ), 15-20 ml hybridization

Table 1. Novel phylotypes

\begin{tabular}{|c|c|c|c|}
\hline Nearest neighbour & Accession no. & Similarity (\%) & Number \\
\hline TM7 phylum sp. oral clone (AF385520) & EU056453 & 97 & 7 \\
\hline TM7 phylum sp. oral clone (AF385520) & EU056470 & 91 & 1 \\
\hline TM7 phylum sp. oral clone (AF385520) & EU056377 & 95 & 4 \\
\hline TM7 phylum sp. oral clone (AF385520) & EU056486 & 96 & 1 \\
\hline TM7 phylum sp. oral clone (AF385520) & EU056499 & 94 & 2 \\
\hline Uncultured bacterium clone (AJ853530) & EU056406 & 89 & 6 \\
\hline Uncultured bacterium clone (AJ853530) & EU056403 & 90 & 9 \\
\hline Uncultured bacterium clone (AJ853530) & EU056514 & 88 & 1 \\
\hline Uncultured soil bacterium clone (AF507686) & EU056494 & 90 & 4 \\
\hline Uncultured bacterium Noosa (AF269022) & EU056458 & 88 & 2 \\
\hline Uncultured soil bacterium clone (AF507686) & EU056375 & 88 & 3 \\
\hline Uncultured soil bacterium clone (AF507686) & EU056419 & 87 & 2 \\
\hline Uncultured soil bacterium clone (AF507686) & EU056420 & 89 & 1 \\
\hline TM7 phylum sp. oral clone (AF432141) & EU056500 & 96 & 1 \\
\hline TM7 phylum sp. oral clone (AF432141) & EU056392 & 97 & 3 \\
\hline TM7 phylum sp. oral clone (AF432141) & EU056508 & 95 & 1 \\
\hline Uncultured bacterium clone (DQ521559) & EU056483 & 94 & 1 \\
\hline Uncultured bacterium clone (DQ521559) & EU056400 & 89 & 1 \\
\hline Uncultured soil bacterium clone (AF507687) & EU056516 & 95 & 1 \\
\hline Uncultured soil bacterium clone (AF507687) & EU056490 & 92 & 1 \\
\hline Uncultured bacterium clone (AB200303) & EU056529 & 96 & 1 \\
\hline TM7 phylum sp. oral clone (AF385500) & EU056423 & 97 & 1 \\
\hline TM7 phylum sp. oral clone (AF385500) & EU056416 & 94 & 1 \\
\hline TM7 phylum sp. oral clone (AF385500) & EU056527 & 96 & 1 \\
\hline Uncultured bacterium (AB195911) & EU056371 & 93 & 1 \\
\hline Uncultured bacterium clone (AJ619043) & EU056446 & 93 & 1 \\
\hline Uncultured bacterium clone (AM116752) & EU056386 & 97 & 1 \\
\hline Uncultured bacterium clone (AM292615) & EU056380 & 93 & 1 \\
\hline Uncultured bacterium clone (AB200292) & EU056379 & 94 & 1 \\
\hline Candidate division TM7 (AY331416) & EU056454 & 91 & 1 \\
\hline Uncultured bacterium clone (AJ583163) & EU056493 & 95 & 1 \\
\hline Uncultured bacterium clone (AM116752) & EU056485 & 97 & 1 \\
\hline Uncultured bacterium clone (AM116752) & EU056425 & 93 & 1 \\
\hline Uncultured bacterium clone (AM116752) & EU056528 & 96 & 10 \\
\hline Uncultured soil bacterium clone (DQ248299) & EU056407 & 97 & 6 \\
\hline
\end{tabular}


solution containing $60 \%$ deionized formamide, $10 \%$ dextran sulfate (both Sigma-Aldrich), $2 \times$ standard saline citrate (SSC, $\mathrm{pH}$ 7.0, 0.3 M sodium chloride and $0.03 \mathrm{M}$ sodium citrate) and $0.5 \mathrm{mg}$ of each probe was applied to each tissue section. The slides were placed on a moistened filter paper in a plastic dish. The dish was covered and floated in a water bath at $80{ }^{\circ} \mathrm{C}$ for $10 \mathrm{~min}$ to denature the target DNA, followed by overnight incubation at $37{ }^{\circ} \mathrm{C}$. Slides were washed once for $5 \mathrm{~min}$ in $2 \times$ SSC buffer, once in $2 \times$ SSC containing $50 \%$ formamide and once again in $2 \times$ SSC. The slides were then immersed in PBS containing $0.1 \%$ Triton X-100 and rinsed briefly in PBS. Extra-avidin peroxidase conjugate (Sigma-Aldrich) was added to the tissue and incubated for $30 \mathrm{~min}$ at $37{ }^{\circ} \mathrm{C}$. The slides were then washed once with $2 \times$ SSC buffer for $5 \mathrm{~min}$, rinsed briefly in PBS containing $0.1 \%$ Triton $\mathrm{X}-100$, and rinsed in PBS for $3 \mathrm{~min}$. The slides were kept in DAB (3,3'-diaminobenzidine) substrate solution (Vector Laboratories); a brown colour developed within 4-5 min. The enzymic reaction was stopped by placing the slides in distilled water. The slides were air-dried and mounted in mounting medium (Aquatex; Merck). An Axioimager Apotome-equipped microscope was used for microscopy (Zeiss).

\section{RESULTS AND DISCUSSION}

\section{Composition of clone libraries}

In this study, we have detected TM7 bacteria in the human colon using different molecular techniques. Overall, in more than $50 \%$ of the subjects, rDNA from TM7 bacteria could be amplified.

Clone libraries with a total of 235 sequences ( 83 from CD, 75 from UC and 77 from non-IBD controls) were analysed. TM7 molecular 16S rRNA gene signatures could be cloned from mucosal samples of IBD patients $(51.5 \%$ in CD; $52.4 \%$ in UC) and controls (51.6\%), but the formal composition of the clone libraries differed significantly $(P$ $<0.01)$ at a distance level of $2 \%(D=0.02)$ for both the CD and UC patients compared to controls.

Using in situ hybridization of colon tissue sections with a TM7-specific probe, the typical filamentous morphotype of the TM7 bacteria could be demonstrated (Fig. 1).

\section{Phylogenetic analysis and statistical indicators of clone libraries}

Richness and diversity of TM7 bacterial species differed significantly between CD, UC and controls. A high number of novel phylotypes (defined as sequences with less than $98 \%$ similarity to any sequence in a public database) were found in all groups ( $n=34$ for CD, $n=29$ for UC and $n=21$ for controls). Data are shown in Table 1 along with annotation numbers and description.

Based on the BLAST search against the NCBI GenBank database, 84 of 221 clones showed less than $98 \%$ similarity to known database entries and belonged to unknown phylotypes. The majority of clone sequences were close relatives of oral clones. Clones showing $99 \%$ similarity with the oral bacterial clone I025 were detected in UC only. This clone has been suggested as a putative pathogen in oral diseases (Brinig et al., 2003). The relative abundance of different phylotypes in healthy and diseased (CD and UC) mucosal libraries is presented in Fig. 2. The number of

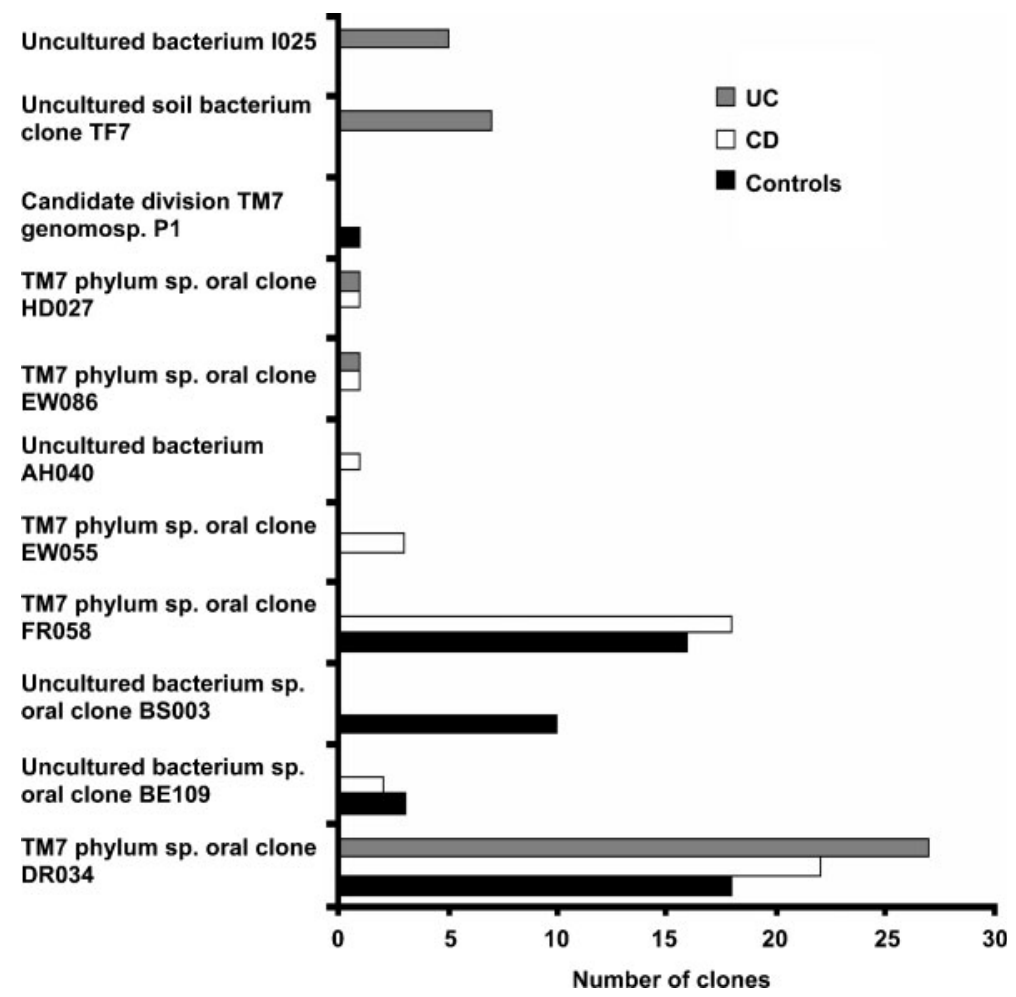

Fig. 2. Relative abundance of different phylotypes in clone libraries from IBD patients and controls. The closest relative (according to database alignment) is plotted versus the number of clones in the specific library. The majority of clone sequences are close relatives of oral clones. Clones showing $99 \%$ similarity with the oral bacterial clone 1025 were detected in UC only. 
novel phylotypes is high owing to the most recent description of this bacterial subgroup. The phylogenetic tree (Fig. 3) was constructed to demonstrate the affiliation of different clones in relation to best hit in NCBI GenBank.

Phylogenetic analysis of the sequences revealed a higher diversity of TM7 OTUs in CD than in UC patients and nonIBD controls at different phylotype levels. Given a cut-off level of $98 \%$ similarity or more for the definition of a phylotype, 23 different OTUs could be identified for CD compared to 10 in the UC group and 12 in the control individuals.

Rarefaction curves were created by plotting the number of OTUs observed on the $y$-axis against the number of sequences sampled on the $x$-axis (Fig. 4). Rarefaction curves plot the total number of individuals counted with repeated samplings versus the total number of OTUs found in those samplings. The result is a curve that increases steeply at first, then gradually levels off. The point at which it levels off is the point where additional sampling is yielding no additional information about the number of OTUs. This is the optimal sample size. Using the formula of Good, coverage of each library was calculated (Table 2).

To determine the estimated richness of TM7 bacteria in the different groups, non-parametric richness estimators ACE and Chao 1 were calculated by DOTUR for every single library and compared with the OTUs observed. For CD, Chao 1 and ACE estimated 47 and 98.70 OTUs while only 23 OTUs were observed (Fig. 5b); Chao 1 and ACE for UC were 11 and 12.06 while the observed OTUs were calculated to be 10 (Fig. 5c). Fig. 5(a) denotes Chao 1 and ACE estimators of OTU richness in healthy control individuals as 15.33 and 24.40, respectively, whereas 12 OTUs were observed for healthy individuals. The number of unseen phylotypes is presented by the gap between observed and estimated (ACE and Chao 1) OTUs.

Simpson's index of diversity $(1 / D)$, which considers both richness and evenness, was used to measure diversity. This

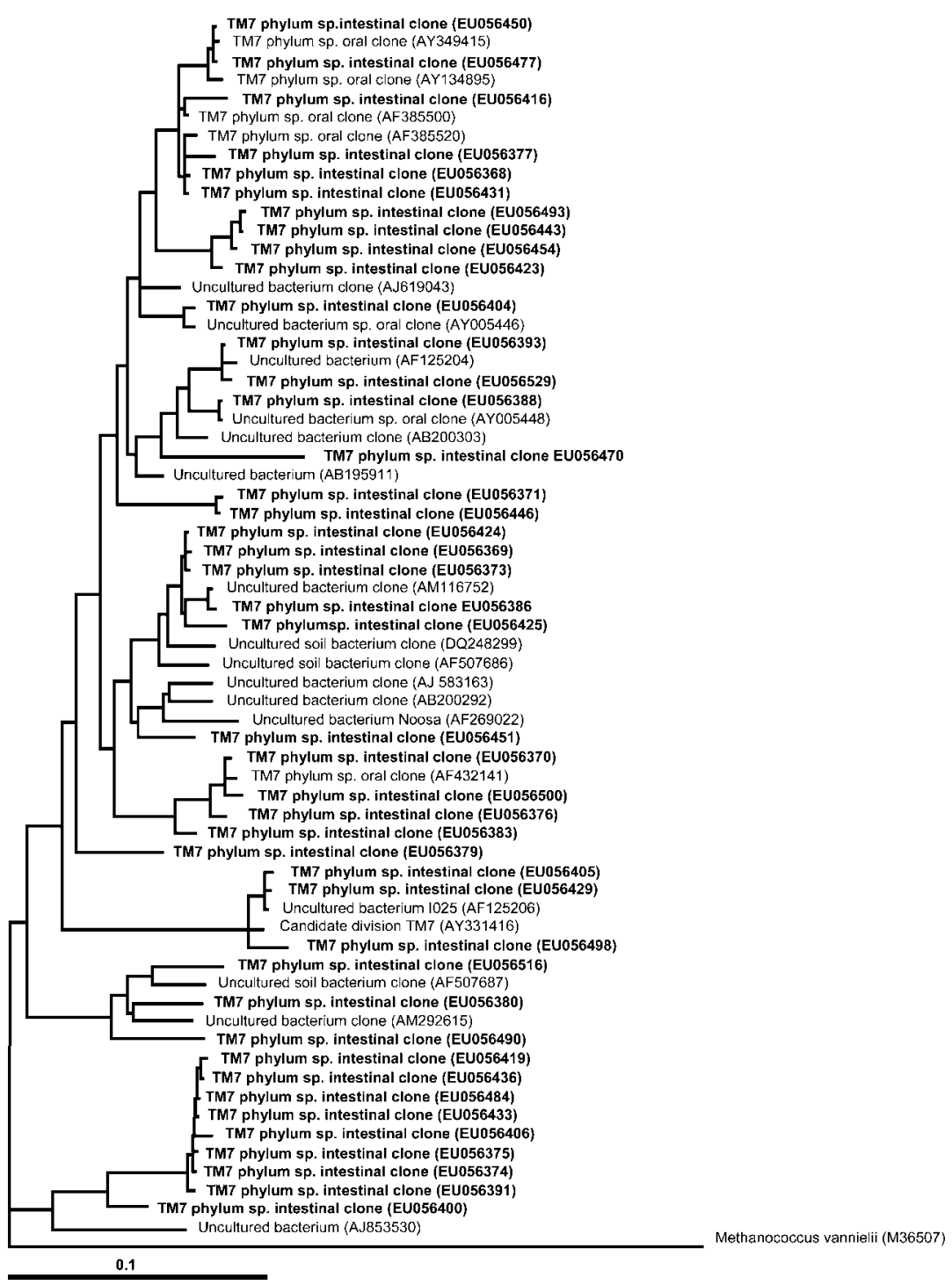

Fig. 3. Phylogenetic tree of the different OTUs demonstrating the affiliation of different clones in relation to the closest relatives identified in public databases. Original clones sequenced in this study including GenBank accession numbers are highlighted in bold. 


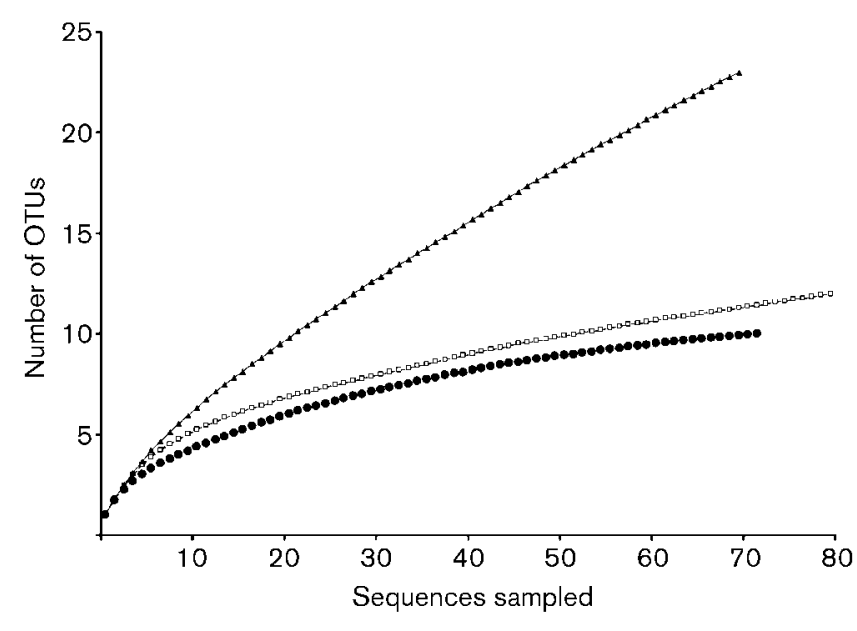

Fig. 4. Rarefaction curves derived from $16 \mathrm{~S}$ rRNA gene clone libraries of CD $(\boldsymbol{\Delta})$ and UC ( $)$ patients and control individuals ( $\square$ ). Clones were grouped into phylotypes at a level of sequence similarity $\geqslant 98 \%$ ( $2 \%$ distance level). The curves show a clear tendency towards reaching a plateau in their end phase, indicating sufficient sampling size of the clone libraries to differentiate even rare phylotypes.

index has been used previously for microbial communities (Katouli et al., 1994; Zhou et al., 2002). It has been suggested that values for $1 / D$ below about 50 indicate typical dominance profiles; therefore, all three libraries showed dominance. Evenness calculated from the Shannon-Weaver index again showed dominance (Table 2).

The intestinal microbiota is characterized by a sensible balance of microbial populations. Bacteria interact with each other (e.g. by quorum sensing) and with the host to maintain this equilibrium (Bassler, 1999; Mai \& Morris, 2004; Sansonetti, 2004; Smith et al., 2000). Previous studies have clearly demonstrated that intestinal dysbiosis plays an important role in the pathophysiology of IBD, with altered bacterial composition and loss of diversity as main characteristics (Manichanh et al., 2006; Ott et al., 2004; Seksik et al., 2003). Reduced diversity is likely to produce a

Table 2. Statistical indicators of clone libraries (distance level 0.02)

\begin{tabular}{|lccc|}
\hline Indicators & CD & UC & Controls \\
\hline Phylotypes & 23 & 10 & 12 \\
Singletons & 16 & 3 & 5 \\
Chao 1 estimator of species richness & 47 & 47 & 15.3 \\
$\quad$ (OTUs) & & & \\
Shannon's index of diversity & 2.3 & 1.56 & 1.85 \\
Simpson's index of diversity 1/D & 5.7 & 3.5 & 5.1 \\
Evenness & 0.54 & 0.36 & 0.42 \\
Good's estimator of coverage (\%) & 77.14 & 95.83 & 93.75 \\
\hline
\end{tabular}

substantial change of local growth conditions with serious effects on the selection pressure of sensitive bacteria. Improved growth conditions due to a loss of selection pressure could be an explanation for the broader spectrum of TM7 species in CD than in control subjects. Most notably, TM7 bacteria have been discussed to modify the local environment towards a more 'inflammatory' biota rather than causing inflammation directly (Brinig et al., 2003). In UC, the diversity of TM7 bacteria was comparable to that of controls, but specific clone IO25 was detected exclusively. Previously, this clone was suggested as a putative specific pathogen for oral disease (Brinig et al., 2003). Our results support that IBD is a bacterial induced disorder, but the pathophysiology of bacterial triggers is likely to be different between the disease entities CD and UC.

\section{Genetically determined resistance to antibiotic therapy}

A highly atypical base substitution for bacterial 16S rRNA genes is associated with antibiotic resistance against streptomycin. A C at position 912 of the consensus $16 \mathrm{~S}$ rRNA gene sequence is responsible for sensitivity of most eubacteria (except TM7) to streptomycin. In archaea and TM7 bacterial divisions, a noncanonical substitution of $912 \mathrm{C} \rightarrow \mathrm{U}$ is linked to antibiotic resistance against streptomycin (Hugenholtz et al., 2001). We have found a C at position 912 in $34.9 \%$ of clones in control subjects, compared to in only $2.7 \%$ of clones in CD patients and none in UC patients.

We found that a high percentage of TM7 bacteria in CD and UC patients carry a base substitution, which is thought to be responsible for resistance to antibiotics (streptomycin and other substances). One possible way of conferring antibiotic resistance to bacteria is by $16 \mathrm{~S}$ rRNA gene base substitution. Aminoglycosides are typically RNA-directed antibiotics. There are two major classes of aminoglycosides: a streptamine-containing class, e.g. streptomycin; and those containing 2-deoxystreptamine, such as kanamycin. Aminoglycosides bind to rRNA in the small subunit of the bacterial ribosome. This binding is highly conserved among archaea, bacteria and eukaryotes, but base substitutions in the coding 16S rRNA gene can result in resistance to specific aminoglycoside antibiotics (Recht \& Puglisi, 2001). The occurrence of species with increased resistance to antibiotics in IBD supports our hypothesis of an increase in selection pressure through dysbiosis as one of the main reasons for higher TM7 species variability and the appearance of pathogenic subspecies, such as IO25.

In this study, we highlighted the presence of TM7 bacteria in the human colon. We could demonstrate that the composition of the TM7 bacterial division is altered in patients with active IBD compared to healthy controls. Our results support recent findings that TM7 bacteria may play a role as promoters of inflammation in inflammatory gastrointestinal disorders with environmental influence. 

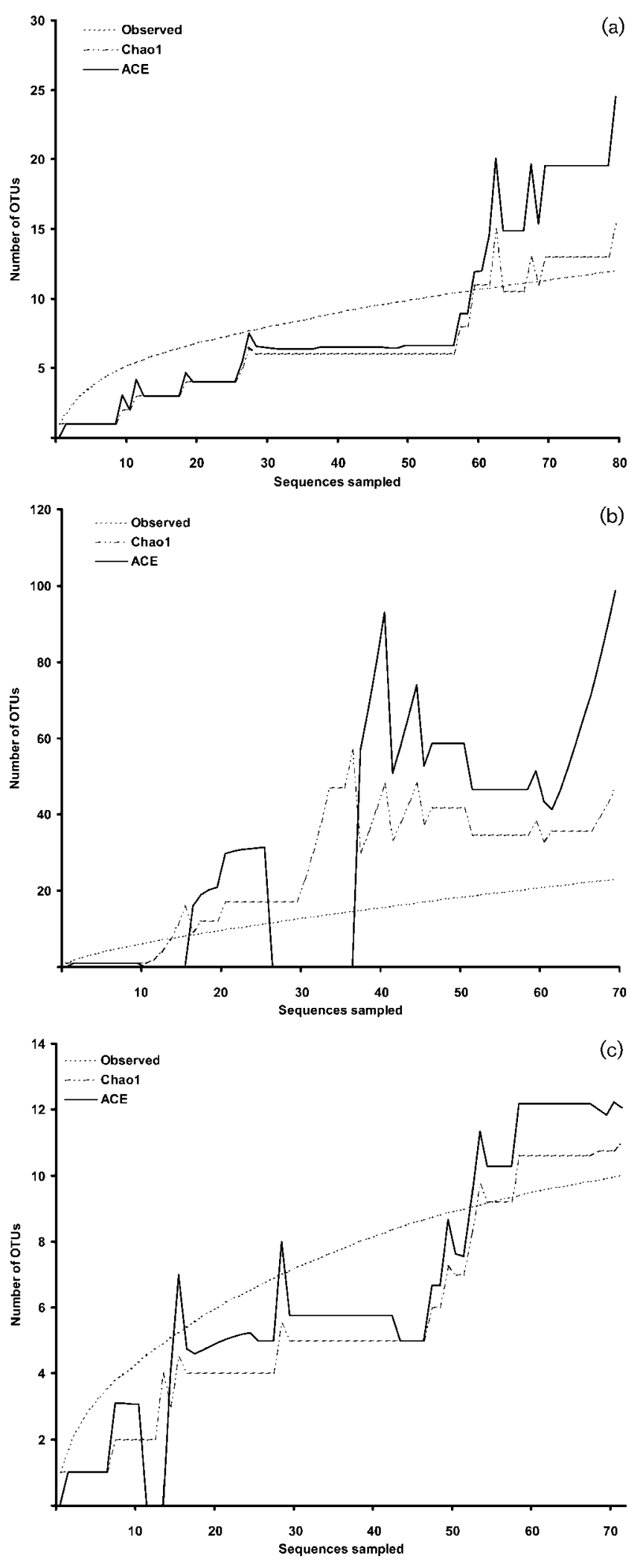

Our results demonstrate that specific bacterial populations, such as TM7, may contribute to a pro-inflammatory shift of the intestinal microbiota. However, it remains to be clarified by metagenomic analysis whether TM7 bacteria
Fig. 5. Collectors curve of observed and estimated phylotype richness using sequences from $\mathrm{CD}$ and $\mathrm{UC}$ patients as well as controls. Non-parametric richness estimators ACE and Chao I were calculated by DOTUR for every single library and compared with the OTUs observed. The figure shows the curves for control (a), CD (b) and UC (c).

trigger inflammation directly or by modulation of the local growth conditions.

\section{ACKNOWLEDGEMENTS}

This work was supported by grants from the German National Genome Research Network (NGFN), the DFG (SFB415) and the EU (EU QLG2-CT-2001-02161). We gratefully acknowledge Ulrike Panknin for her excellent work with the generation of clone libraries and sequencing.

\section{REFERENCES}

Bassler, B. L. (1999). How bacteria talk to each other: regulation of gene expression by quorum sensing. Curr Opin Microbiol 2, 582-587.

Brinig, M. M., Lepp, P. W., Ouverney, C. C., Armitage, G. C. \& Relman, D. A. (2003). Prevalence of bacteria of division TM7 in human subgingival plaque and their association with disease. Appl Environ Microbiol 69, 1687-1694.

Chapman, R. W., Selby, W. S. \& Jewell, D. P. (1986). Controlled trial of intravenous metronidazole as an adjunct to corticosteroids in severe ulcerative colitis. Gut 27, 1210-1212.

Cole, J. R., Chai, B., Marsh, T. L., Farris, R. J., Wang, Q., Kulam, S. A., Chandra, S., McGarrell, D. M., Schmidt, T. M. \& other authors (2003). The Ribosomal Database Project (RDP-II): previewing a new autoaligner that allows regular updates and the new prokaryotic taxonomy. Nucleic Acids Res 31, 442-443.

Eckburg, P. B. \& Relman, D. A. (2007). The role of microbes in Crohn's disease. Clin Infect Dis 44, 256-262.

Forghani, B., Dupuis, K. W. \& Schmidt, N. J. (1985). Rapid detection of herpes simplex virus DNA in human brain tissue by in situ hybridization. J Clin Microbiol 22, 656-658.

Geboes, K. \& Dalle, I. (2002). Influence of treatment on morphological features of mucosal inflammation. Gut 50 (Suppl. 3), iii37-iii42.

Geboes, K., Riddell, R., Ost, A., Jensfelt, B., Persson, T. \& Lofberg, R. (2000). A reproducible grading scale for histological assessment of inflammation in ulcerative colitis. Gut 47, 404-409.

Good, I. J. (1953). The population frequencies of species and the estimation of the population parameters. Biometrika 40, 237-264.

Hooper, L. V. \& Gordon, J. I. (2001). Commensal host-bacterial relationships in the gut. Science 292, 1115-1118.

Hooper, L. V., Bry, L., Falk, P. G. \& Gordon, J. I. (1998). Hostmicrobial symbiosis in the mammalian intestine: exploring an internal ecosystem. Bioessays 20, 336-343.

Hugenholtz, P., Goebel, B. M. \& Pace, N. R. (1998). Impact of culture-independent studies on the emerging phylogenetic view of bacterial diversity. J Bacteriol 180, 4765-4774.

Hugenholtz, P., Tyson, G. W., Webb, R. I., Wagner, A. M. \& Blackall, L. L. (2001). Investigation of candidate division TM7, a recently recognized major lineage of the domain bacteria with no known pureculture representatives. Appl Environ Microbiol 67, 411-419. 
Katouli, M., Bark, T., Ljungqvist, O., Svenberg, T. \& Mollby, R. (1994). Composition and diversity of intestinal coliform flora influence bacterial translocation in rats after hemorrhagic stress. Infect Immun 62, 4768-4774.

Kerstens, H. M., Poddighe, P. J. \& Hanselaar, A. G. (1994). Doubletarget in situ hybridization in brightfield microscopy. J Histochem Cytochem 42, 1071-1077.

Kumar, P. S., Griffen, A. L., Barton, J. A., Paster, B. J., Moeschberger, M. L. \& Leys, E. J. (2003). New bacterial species associated with chronic periodontitis. J Dent Res 82, 338-344.

Mai, V. \& Morris, J. G., Jr (2004). Colonic bacterial flora: changing understandings in the molecular age. J Nutr 134, 459-464.

Malchow, H., Ewe, K., Brandes, J. W., Goebell, H., Ehms, H., Sommer, H. \& Jesdinsky, H. (1984). European Cooperative Crohn's Disease Study (ECCDS): results of drug treatment. Gastroenterology 86, 249-266.

Manichanh, C., Rigottier-Gois, L., Bonnaud, E., Gloux, K., Pelletier, E., Frangeul, L., Nalin, R., Jarrin, C., Chardon, P. \& other authors (2006). Reduced diversity of faecal microbiota in Crohn's disease revealed by a metagenomic approach. Gut 55, 205-211.

Marteau, P. (2000). Role of the intestinal flora in gastrointestinal diseases. Lancet 356, s28.

Ott, S. J., Musfeldt, M., Wenderoth, D. F., Hampe, J., Brant, O., Folsch, U. R., Timmis, K. N. \& Schreiber, S. (2004). Reduction in diversity of the colonic mucosa associated bacterial microflora in patients with active inflammatory bowel disease. Gut 53, 685-693.

Ott, S. J., El Mokhtari, N. E., Musfeldt, M., Hellmig, S., Freitag, S., Rehman, A., Kuhbacher, T., Nikolaus, S., Namsolleck, P. \& other authors (2006). Detection of diverse bacterial signatures in atherosclerotic lesions of patients with coronary heart disease. Circulation 113, 929-937.

Ouverney, C. C., Armitage, G. C. \& Relman, D. A. (2003). Single-cell enumeration of an uncultivated TM7 subgroup in the human subgingival crevice. Appl Environ Microbiol 69, 6294-6298.
Recht, M. I. \& Puglisi, J. D. (2001). Aminoglycoside resistance with homogeneous and heterogeneous populations of antibiotic-resistant ribosomes. Antimicrob Agents Chemother 45, 2414-2419.

Sansonetti, P. J. (2004). War and peace at mucosal surfaces. Nat Rev Immunol 4, 953-964.

Schloss, P. D. \& Handelsman, J. (2005). Introducing DOTUR, a computer program for defining operational taxonomic units and estimating species richness. Appl Environ Microbiol 71, 1501-1506.

Schloss, P. D., Larget, B. R. \& Handelsman, J. (2004). Integration of microbial ecology and statistics: a test to compare gene libraries. Appl Environ Microbiol 70, 5485-5492.

Schreiber, S., Rosenstiel, P., Albrecht, M., Hampe, J. \& Krawczak, M. (2005). Genetics of Crohn disease, an archetypal inflammatory barrier disease. Nat Rev Genet 6, 376-388.

Seksik, P., Rigottier-Gois, L., Gramet, G., Sutren, M., Pochart, P., Marteau, P., Jian, R. \& Dore, J. (2003). Alterations of the dominant faecal bacterial groups in patients with Crohn's disease of the colon. Gut 52, 237-242.

Singleton, D. R., Furlong, M. A., Rathbun, S. L. \& Whitman, W. B. (2001). Quantitative comparisons of 16S rRNA gene sequence libraries from environmental samples. Appl Environ Microbiol 67, 4374-4376.

Smith, S., Vaughan, E. E. \& De Vos, W. M. (2000). Quorum sensing within the gut. Microb Ecol Health Dis 2 (Suppl.), 81-92.

Thompson, J. D., Gibson, T. J., Plewniak, F., Jeanmougin, F. \& Higgins, D. G. (1997). The CLUSTAL_X windows interface: flexible strategies for multiple sequence alignment aided by quality analysis tools. Nucleic Acids Res 25, 4876-4882.

Wang, M., Ahrne, S., Jeppsson, B. \& Molin, G. (2005). Comparison of bacterial diversity along the human intestinal tract by direct cloning and sequencing of 16S rRNA genes. FEMS Microbiol Ecol 54, 219-231.

Zhou, J., Xia, B., Treves, D., Wu, L., Marsh, T., O’Neill, R., Palumbo, A. \& Tiedje, J. (2002). Spatial and resource factors influencing high microbial diversity in soil. Appl Environ Microbiol 68, 326-334. 